\title{
त्र
}

Sammlung Metzler

Band 243 
Gerhard R. Kaiser

\section{E.T.A. Hoffmann}

J. B. Metzlersche Verlagsbuchhandlung Stuttgart 


\section{CIP-Kurztitelaufnahme der Deutschen Bibliothek}

Kaiser, Gerhard R.:

E.T. A. Hoffmann / Gerhard R. Kaiser.

- Stuttgart : Metzler, 1988

(Sammlung Metzler; Bd. 243)

ISBN 978-3-476-10243-0

NE: GT

ISBN 978-3-476-10243-0

ISBN 978-3-476-03945-3 (eBook)

DOI 10.1007/978-3-476-03945-3

ISSN 05583667

\section{SM 243}

Dieses Werk einschließlich aller seiner Teile ist urheberrechtlich geschützt. Jede Verwertung außerhalb der engen Grenzen des Urheberrechtsgesetzes ist ohne Zustimmung des Verlages unzulässig und strafbar. Das gilt insbesondere für Vervielfältigungen, Übersetzungen, Mikroverfilmungen und die Einspeicherung und Verarbeitung in elektronischen Systemen.

(C) 1988 Springer-Verlag GmbH Deutschland Ursprünglich erschienen bei J. B. Metzlersche Verlagsbuchhandlung und Carl Ernst Poeschel Verlag GmbH in Stuttgart 1988 


\section{Vorwort}

Dieser Band beansprucht nicht, jene vollständige und aktualisierte Hoffmann-Bibliographie zu sein, die Hans-Dieter Holzhausen unlängst zu Recht als Forschungsdesiderat genannt hat (MHG 30, 1984, 73-82); wohl aber war ich bestrebt, die wichtigste kritische Literatur nach dem fast ausnahmslos durch Autopsie bestätigten Rang aufzuführen und den Benutzer rasch über den aktuellen Diskussionsstand zu informieren.

Gewidmet ist der Band Günter und Ingrid Oesterle in dankbarer und herzlicher Verbundenheit. 


\section{Inhalt}

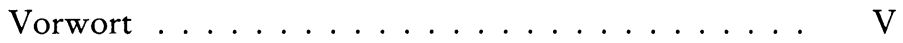

1. Materialien ................... 1

1.1. Nachlaß, Handschriften . . . . . . . . . 1

1.2. Ausgaben .................. 1

1.2.1. Literarische Werke, Schriften zur Musik . . . 1

1.2.2. Briefe, Tagebücher . . . . . . . . . . 4

1.2.3. Musikalische Werke ............ 5

1.2.4. Zeichnungen, Gemälde . . . . . . . . 5

1.2.5. Juristische Arbeiten $\ldots \ldots \ldots \ldots \ldots 6$

1.3. Hilfsmittel . . . . . . . . . . . . . 6

1.3.1. Bibliographien, Forschungsberichte, Mitteilungen der E. T. A. Hoffmann-Gesellschaft . . . 6

1.3.2. Dokumentation, Register, Bildmaterial . . . . 7

1.3.3. Kritische Literatur (Auswahl) . . . . . . . . 8

1.3.3.1. Monographien, Sammelbände . . . . 8

1.3.3.2. Kürzere Beiträge . . . . . . . . 12

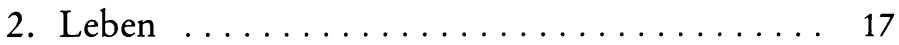

2.1. Königsberg (1776-1796) . . . . . . . . . . 17

2.2. Glogau, Berlin, Posen, Płock, Warschau, Berlin (1796-1808) . . . . . . . . . . . . . 20

2.3. Bamberg (1808-1813) . . . . . . . . . . . 24

2.4. Dresden, Leipzig (1813-1814) . . . . . . . . 25

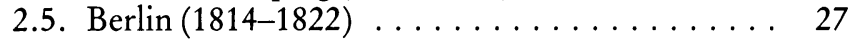

3. Literarisches Werk, Schriften zur Musik,

Briefe und Tagebücher, Zuschreibungen . . . . . 33

3.1. Literarisches Werk . . . . . . . . . . . . . . 33

3.1.1. "Fantasiestücke in Callots Manier « . . . . . . 33

3.1.2. "Die Elixiere des Teufels« . . . . . . . . . . . 45

3.1.3. "Nachtstücke« . . . . . . . . . . . . . 51

3.1.4. "Seltsame Leiden eines Theater-Direktors« . . . 62

3.1.5. "Die Serapions-Brüder« . . . . . . . . . . . . . 64

3.1.6. "Lebens-Ansichten des Katers Murr nebst fragmentarischer Biographie des Kapellmeisters Johannes Kreisler in zufälligen Makulaturblättern« . . . . . . . . . . . 86 
3.1.7. "Späte Werke« . . . . . . . . . . . . . 92

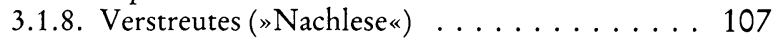

3.2. »Schriften zur Musik« . . . . . . . . . . . . . . . 109

3.3. Briefe .................... 113

3.4. Tagebücher ................ 114

3.5. Zuschreibungen $\ldots \ldots \ldots \ldots \ldots \ldots \ldots$

4. Systematische Forschungsaspekte . . . . . . . . . 119

4.1. Die Auseinandersetzung mit zeitgenössischen

Diskursen . . . . . . . . . . . . . . . . . 119

4.1.1. Verhältnis zur romantischen Naturund Geschichtsphilosophie . . . . . . . . . 119

4.1.2. Hoffmann als Jurist . . . . . . . . . . . . . 122

4.1.3. Hoffmann und die zeitgenössische

Medizin . . . . . . . . . . . . . . . . . 125

4.2. Die Wahl zwischen den Künsten . . . . . . . . 127

4.2.1. Entscheidung für die Literatur . . . . . . . . . 127

4.2.2. Hoffmann als Musiker und die

Bedeutung der Musik für sein

literarisches Schaffen . . . . . . . . . . . . 128

4.3. Poetologie . . . . . . . . . . . . . . . 132

4.3.1. "Serapiontisches Prinzip" . . . . . . . . . . 133

4.3.2. »Besonnenheit $«$. . . . . . . . . . . . . 134

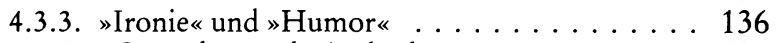

4.3.4. "Groteske« und $»$ Arabeske . . . . . . . . . . . 137

4.3.5. »Fülle«, »fester Kern«, »Kaleidoskop« . . . . . 139

4.4. Poetik . . . . . . . . . . . . . . . . . 142

4.4.1. Erzählpersonal und Handlungsschemata . . . 142

4.4.2. Motive . . . . . . . . . . . . . . . . . 144

4.4.3. Bildlichkeit . . . . . . . . . . . . . . 145

4.4.3.1. Verbale Bildlichkeit . . . . . . . . 145

4.4.3.2. Bedeutung der bildenden Kunst

für den Erzähler Hoffmann . . . . . . . 146

4.4.4. Affinität zum Drama . . . . . . . . . . . . . 147

4.4.4.1. Szenisches Erzählen . . . . . . . . 147

4.4.4.2. Bedeutung von Drama und Bühne für den Erzähler Hoffmann . . . . . . . 148

4.4.5. Schockmetaphorik und Synästhesien . . . . . . . 149

4.4.6. Modalisierung und Perspektivismus . . . . . . 151

4.4.7. Zitathafte Sprache . . . . . . . . . . . . . 152

4.4.8. Autothematik . . . . . . . . . . . . . 154

4.4.9. Leserlenkung . . . . . . . . . . . . . 155

4.5. Binnendifferenzierung des erzählerischen

Werkes ................... 155

4.6. Entwicklung . . . . . . . . . . . . . 157

4.7. Literarische Quellen . . . . . . . . . . . . 158 


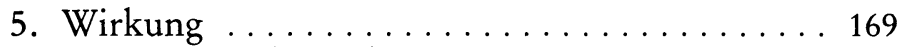

5.1. Literarische Wirkung . . . . . . . . . . . . . 169

5.1.1. Deutsches Sprachgebiet . . . . . . . . . . . 169

5.1.2. Schottland, England, USA _. . . . . . . . . 177

5.1.3. Frankreich . . . . . . . . . . . . . . . 180

5.1.4. Rußland / Sowjetunion . . . . . . . . . . . 184

5.1.5. Andere Länder . . . . . . . . . . . . . 188

5.2. Musik / Musikkritik . . . . . . . . . . . . . 190

5.3. Bildende Kunst / Illustrationen . . . . . . . . . 193

6. Geschichte, Schwerpunkte und

Desiderate der Forschung . . . . . . . . . . . . 197

6.1. Grundlagensicherung . . . . . . . . . . . . 197

6.2. »Geistesgeschichtliche«Syntheseversuche

bei fortschreitender Differenzierung . . . . . . . . 199

6.3. Weitere Differenzierung,

Ansätze zu neuer Synthese . . . . . . . . . . . 201

6.4. Desiderate der Forschung . . . . . . . . . . . 204

Register der literarischen Werke H.s

(einschließlich der Libretti) . . . . . . . . . . . 205

Personenregister . . . . . . . . . . . . . . . 208 


\section{Abkürzungen}

Zitierte Ausgaben:

FN Fantasiestücke in Callots Manier. Nachtstücke. Seltsame Leiden eines Theater-Direktors (Winkler)

EM Die Elixiere des Teufels. Lebens-Ansichten des Katers Murr (Winkler)

SB Die Serapions-Brüder (Winkler)

SW Späte Werke (Winkler)

M Schriften zur Musik (Winkler)

N Nachlese (Winkler)

HKA Historisch-kritische Ausgabe von Maassens

W Sämtliche Werke (Deutscher Klassiker Verlag)

B Briefwechsel

DüD E.T. A. Hoffmann. Dichter über ihre Dichtungen

JA Juristische Arbeiten

T Tagebücher

Bandzahl römisch, Seitenzahl arabisch.

Zeitschriften, Jabrbiicher

AMZ Allgemeine musikalische Zeitung

Archiv Archiv für das Studium der neueren Sprachen und Literaturen

$\mathrm{CL} \quad$ Comparative Literature

CG Colloquia Germanica

DU Der Deutschunterricht (Stuttgart)

DVjs Deutsche Vierteljahrsschrift

EG Etudes germaniques

GLL German life and letters

GQ The German quarterly

GR The Germanic review

GSR German studies review

GRM Germanisch-romanische Monatsschrift

JbdSG Jahrbuch der deutschen Schiller-Gesellschaft

JWGV Jahrbuch des Wiener Goethe-Vereins

JEGP Journal of English and Germanic Philology

LJ Literaturwissenschaftliches Jahrbuch der Görres-Gesellschaft

MHG Mitteilungen der E.T. A. Hoffmann-Gesellschaft

MLN Modern language notes

MLQ Modern language quarterly 
MLR The modern language review

Monats- Monatshefte für deutschen Unterricht, deutsche Sprache und hefte Literatur

NGS New German studies

PMLA Publications of the Modern Language Association of America

RHLF Revue d'histoire littéraire de la France

RLC Revue de littérature comparée

SiR Studies in Romanticism

WB Weimarer Beiträge

WW Wirkendes Wort

ZfdPh Zeitschrift für deutsche Philologie

Die übrigen Abkürzungen nach den in 1.2. nachgewiesenen Ausgaben und der in 1.3. bzw. im Anhang zu den einzelnen Abschnitten aufgeführten kritischen Literatur:

[Rat Krespel] heißt: Titel nicht von Hoffmann. 